ARTICLE

Received 4 Nov 2014 | Accepted 29 Jan 2015 | Published 5 Mar 2015

DOI: $10.1038 /$ ncomms7456 OPEN

\title{
Highly specific in vivo gene delivery for p53-mediated apoptosis and genetic photodynamic therapies of tumour
}

\author{
S.-Ja Tseng ${ }^{1, \star}$, Zi-Xian Liao ${ }^{2, \star}$, Shih-Han Kao ${ }^{3}$, Yi-Fang Zeng ${ }^{4}$, Kuo-Yen Huang ${ }^{5}$, Hsin-Jung Li ${ }^{5}$, Chung-Lin Yang ${ }^{6}$, \\ Yu-Fan Deng ${ }^{7}$, Chi-Feng Huang ${ }^{8}$, Shuenn-Chen Yang ${ }^{9}$, Pan-Chyr Yang ${ }^{1,9,10}$ \& Ivan M. Kempson ${ }^{11}$
}

Anticancer therapies are often compromised by nonspecific effects and challenged by tumour environments' inherent physicochemical and biological characteristics. Often, therapeutic effect can be increased by addressing multiple parameters simultaneously. Here we report on exploiting extravasation due to inherent vascular leakiness for the delivery of a $\mathrm{pH}$-sensitive polymer carrier. Tumours' acidic microenvironment instigates a charge reversal that promotes cellular internalization where endosomes destabilize and gene delivery is achieved. We assess our carrier with an aggressive non-small cell lung carcinoma (NSCLC) in vivo model and achieve $>30 \%$ transfection efficiency via systemic delivery. Rejuvenation of the p53 apoptotic pathway as well as expression of KillerRed protein for sensitization in photodynamic therapy (PDT) is accomplished. A single administration greatly suppresses tumour growth and extends median animal survival from 28 days in control subjects to 68 days. The carrier has capacity for multiple payloads for greater therapeutic response where inter-individual variability can compromise efficacy.

\footnotetext{
${ }^{1}$ Department of Internal Medicine, National Taiwan University College of Medicine, Taipei 10051, Taiwan. ${ }^{2}$ Institute of Medical Science and Technology, National Sun Yat-sen University, Kaohsiung 80424, Taiwan. ${ }^{3}$ Research Center for Tumor Medical Science, China Medical University, Taichung 40402 Taiwan. ${ }^{4}$ Institute of Biotechnology, National Taiwan University, Taipei 10617, Taiwan. ${ }^{5}$ Graduate Institute of Life Sciences, National Defense Medical Center, Taipei 11490, Taiwan. ${ }^{6}$ Departments of Neurosurgery, Chang Gung Memorial Hospital, Taoyuan 33305, Taiwan. ${ }^{7}$ Department of Industrial and System Engineering, Chung Yuan Christian University, Taoyuan 32023, Taiwan. ${ }^{8}$ Institute of Physics, Academia Sinica, Taipei 11529, Taiwan. ${ }^{9}$ Institute of Biomedical Sciences, Academia Sinica, Taipei 11529, Taiwan. ${ }^{10}$ NTU Center for Genomic Medicine, National Taiwan University, Taipei 10051, Taiwan. ${ }^{11}$ lan Wark Research Institute, University of South Australia, Mawson Lakes, South Australia 5095, Australia. * These authors contributed equally to this work. Correspondence and requests for materials should be addressed to P.-C.Y. (email: pcyang@ntu.edu.tw) or to I.M.K. (email: Ivan.Kempson@unisa.edu.au).
} 
T he mutation and dysfunction of protein 53 (p53) has been associated with over $50 \%$ of human cancers ${ }^{1}$. Mutant p 53 not only loses tumour suppressive abilities ${ }^{2}$, but additionally leads to promotion of tumorigenesis ${ }^{3}$. Replacement of the genetic aberrance in cancer cells is one of the most promising therapeutic approaches ${ }^{4-7}$. It is clear that p53 has great significance in cancer growth and therapy. In a specific example, p53 suppressed cancer invasion by prompting the degradation of Slug protein, an invasion promoter in patients with non-small cell lung cancer (NSCLC) ${ }^{8}$. Mutant p53 compromises Slug degradation, resulting in Slug accumulation and cancer invasiveness. In addition, cellular generation of reactive oxygen species (ROS) can act either upstream or downstream of p53mediated apoptosis9. Studies have shown that ROS increases c-myc, which inhibits cell cycle arrest but does not influence p53transactivated pro-apoptosis gene, PUMA ${ }^{10}$. ROS can also enhance the post-translational modification of $\mathrm{p} 53$, such as phosphorylation and acetylation, both of which lead to p53 protein stabilization and activation ${ }^{11}$. On the contrary, the overexpression of $\mathrm{p} 53$ transactivates redox active proteins, that is, quinone oxidoreductase (NQO1; ref. 12) and proline oxidase $(\mathrm{POX})^{13}$ and their elevation results in oxidative stress and subsequent cell death. These pieces of evidence show that ROS and p53 pathways are intertwined; excessive amounts of either pathway may augment the other, consequently leading to cell apoptosis. These avenues in the treatment of cancer can be approached with the development of effective gene delivery. Polymeric-based carriers offer great promise, however, they generally fail in attempts to translate in vitro effect to in vivo models ${ }^{14}$. Chemotherapy is one major approach for treating NSCLC; however, progression-free survival rates depend significantly on the individuals' chemotherapy response and extent of tumour metastasis. The genetically-encoded red fluorescent protein (KillerRed) leads to irreversible DNA damage and cell killing via an apoptotic pathway upon irradiation with a narrow light bandwidth of $520-590 \mathrm{~nm}$ due to formation of highly-cytotoxic levels of $\operatorname{ROS}^{15,16}$; offering additional options in treatment of tumour and study of tumour radiosensitization. Most current photodynamic therapy (PDT) regimens are based on a single administration ${ }^{17}$. Thus, successful demonstration here of a carrier for replacement of the aberrant p53 gene in combination with in situ PDT sensitization offers an opportunity for effective gene therapy with a single administration.

Numerous approaches are being taken to reconstitute wild-type p53 expression in tumour and to use the function of the p53 pathway as a reliable predictor of therapy response and patient prognosis ${ }^{4-7}$. Approved studies in the United States implemented p53 gene-based therapies using viral vector delivery, in various clinical settings ${ }^{6,7}$. Side effects were mild but the treatments required local injection into the tumour site and may not be effective in all patients compared with current best standard of care, especially after metastasis. Attempts to improve the efficacy by modifying p53 and enhancing delivery remain challenging. Among various polymeric carriers available, polyethylenimine (PEI) was utilized to transfer genes for in vitro and in vivo transfection ${ }^{18}$. Modified PEI has been found to be reasonably biocompatible ${ }^{18}$. Alternatively, the incorporation of negatively charged polymer into the original polymeric formulation has also enhanced the cellular uptake and transfection efficiency (TE $)^{16,19}$. However, a challenge in implementation concerns its lack of specificity in targeting tumour and cellular uptake from systemic administration.

$\mathrm{pH}$-sensitive activation and delivery is proving to be an attractive trigger for greater efficacy in treatment of tumour. Particular attention targets $\mathrm{pH}$-responsive carriers/materials exploiting acidic microenvironments ${ }^{20-22}$. In solid tumour, accumulation of lactic acid leads to slight lowering of extracellular $\mathrm{pH}(\sim \mathrm{pH} 6.7-7.0$; ref. 23). The low tumour $\mathrm{pH}$ primarily results from a high rate of glycolysis, which can produce acids under both aerobic and anaerobic conditions. We previously developed highly $\mathrm{pH}$-sensitive complexes of 150 250-nm diameter carriers and hydrogels for controllable transfection $^{24}$ or extracellular delivery $y^{20,22,25}$. Here we present an improved technique that switches to promote cellular uptake and delivery of plasmid DNA of p53 and KillerRed triggered by tumour acidosis in vivo (Fig. 1a). Negatively charged DNAcomplexes were formed with plasmid DNAs, branched PEI $\left(\mathrm{bPEI}_{25 \mathrm{~K}}, \mathrm{Mw}=25,000\right.$ ) and poly (poly(ethylene glycol; PEG-HisPEG-Glu) consisting of tuned ratios of PEG, histidine (His) and glutamic acid (Glu) (Supplementary Fig. 1). In this work we make a comparison between this carrier, which we term as the DNAcomplex (with tuned $\mathrm{pH}$ response), with a bPEI25k/DNAcomplex (which lacks the PEG and amino acid residues and resulting $\mathrm{pH}$ sensitivity). Exposure of the DNA-complex to acidic $\mathrm{pH}(\mathrm{pH}=6.8)$ triggers protonation of the amino groups and an in situ charge reversal, leading to cellular uptake and transfection. The zeta potential of the DNA-complex recovers once the environment returns from acid to neutral $\mathrm{pH}$. Such a carrier is highly versatile in its loading as well as effective in being responsive to the 'targeted' tumour tissue microenvironment from systemic administration. In the present study, we simultaneously rejuvenate the p53-mediated apoptosis signalling pathway and enable photoinduced ROS generation; effectively suppressing tumour growth of an aggressive human NSCLC cell line (H1299) in athymic BALB/c nude mice.

\section{Results}

Characterization of $\mathbf{p H}$-dependent regulation. Zeta potential and size of DNA-complexes were measured by dynamic light scattering and the formation of the DNA-complex was verified by the changes in the surface charge and particle size at various $\mathrm{pH}$ values. The zeta potential varied between negative and positive values ( $-31 \pm 3.7$ to $15 \pm 3.5 \mathrm{mV}$ at $\mathrm{pH} 7.4$ ) depending on the change of weight ratio of $\mathrm{bPEI}_{25 \mathrm{~K}} / \mathrm{DNA} / \mathrm{poly}$ (PEG-His 0.5 -PEG$\mathrm{Glu}_{0.5}$ ) from $0.5 / 1 / 1$ to $2 / 1 / 1$ (Fig. 1b). Specifically, the extent of protonated amine groups of DNA-complexes increases with a decrease in $\mathrm{pH}$ from 7.4 to 6.5 , which in turn, increases positivecharge density on the DNA-complex. Interestingly, the change from a negatively charged DNA-complex to positively charged could be tuned to occur when the $\mathrm{pH}$ value changed from 7.4 to 6.8 at $0.5 / 1 / 1(\mathrm{w} / \mathrm{w} / \mathrm{w})$, indicating that the in situ charge reversal of DNA-complex can be achieved in an in vivo-relevant $\mathrm{pH}$ range for the tumour microenvironment. Such a change of the zeta potential augments the DNA-complex cellular interaction and consequently greater cellular uptake $\mathrm{e}^{24,25}$. In various formulations of the DNA-complex's weight ratios, the spherical DNA-complex had a diameter of $c a \cdot 100-200 \mathrm{~nm}$ over a wide range of $\mathrm{pH}$ (Fig. 1c and Supplementary Fig. 2). Following treatments, we examined effect of the DNA-complex and $\mathrm{bPEI}_{25 \mathrm{~K}} / \mathrm{DNA}$ complex on cell viability. An improved biocompatibility for lower ratios of PEI may be attributed to a more appeasing net charge (Supplementary Fig. 3$)^{19,24,25}$. Taken together, the DNA-complex at the optimized weight ratio of $0.5 / 1 / 1$ was suited to efficiently express p53 and KillerRed in tumour for localized cellular uptake and triggered functionality. Comparisons were made to the bPEI25k/DNA-complex as a control, having a $2 / 1$ ratio, which was optimal for the maximum transfection in vitro.

Consequently, to evaluate the effect of $\mathrm{pH}$ on cellular uptake of the DNA-complex, the pCMV-p53 and pKillerRed-mem were labelled with fluorescein as a detection signal for flow cytometry. For the DNA-complex, fluorescence intensity increased when cells 


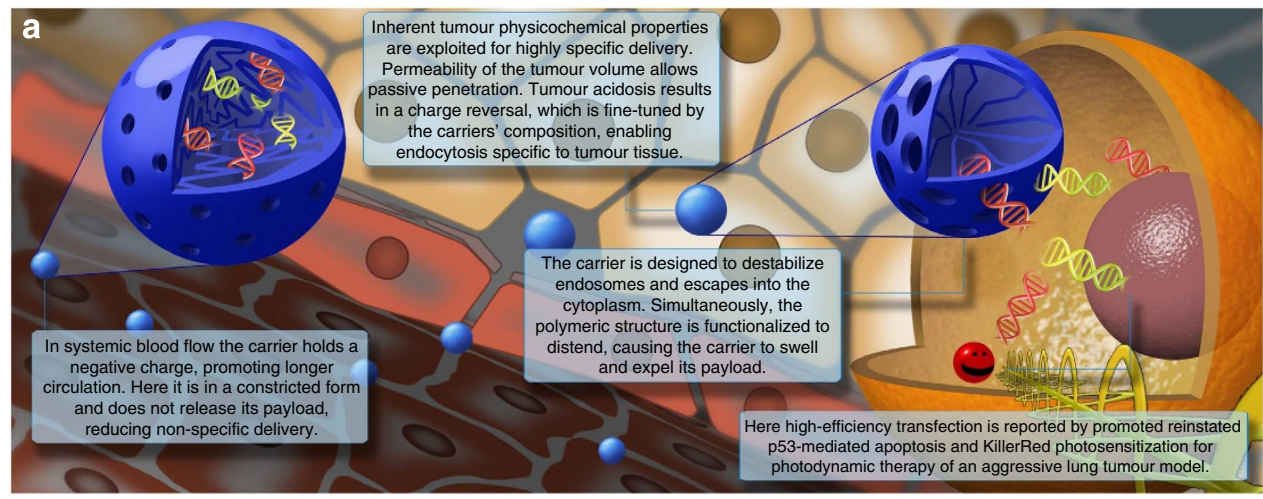

b

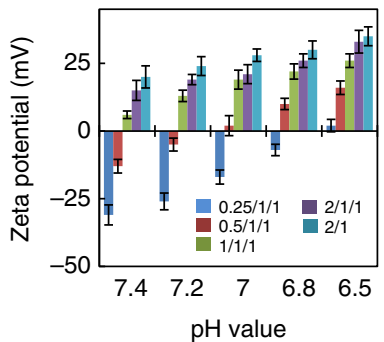

C

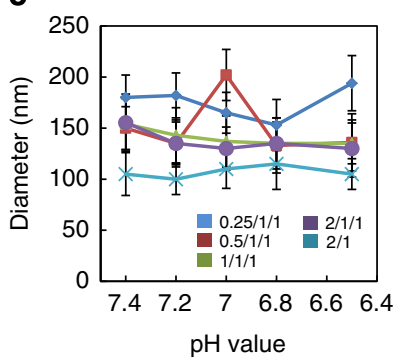

d

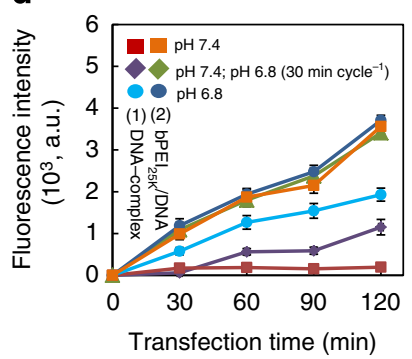

Figure 1 | A highly pH-sensitive carrier. (a) A schematic representation of the gene loaded carrier. Its biocompatible, contracted, negatively charged form circulates freely in a passive form until extravasation into tumour tissue characterized by lowered $\mathrm{pH}$. Tumour acidosis switches the carriers charge to enhance cellular interaction and uptake. Protonation of the carriers' amino groups leads to distention of the polymer chains, dilation and expulsion of payloads. Here p53 and KillerRed genes transfect tumour cells. p53 triggers apoptosis while illumination of KillerRed protein generates ROS and subsequent intracellular damage, further promoting cell apoptosis. (b,c) $\zeta$-Potential (b) and hydrodynamic diameter (c) of the DNA-complex and bPEI $25 \mathrm{~K} / \mathrm{DNA}$ complex as a function of $\mathrm{pH}$ for varying $\mathrm{bPEI}_{25 \mathrm{~K}} / \mathrm{DNA} /$ copolymer weight ratios. Data show the mean of the measurements conducted in triplicate $\pm \mathrm{s}$. $\mathrm{d}$. (d) Fluorescence intensity after cellular uptake of the $\mathrm{bPEI}_{25 \mathrm{~K}} / \mathrm{DNA}$-complex (bPEI ${ }_{25 \mathrm{~K}} / \mathrm{DNA}$ weight ratio: 2/1) or DNA-complex (bPEI $25 \mathrm{~K} / \mathrm{DNA} / \mathrm{copolymer}$ weight ratio: 0.5/1/1) monitored using Alexa Fluor 488 labelling of plasmid DNAs over the period of several cycles of pH between 7.4 and 6.8 or incubated at only pH 7.4 or 6.8 . Results show mean of measurements conducted in triplicate \pm s.d. Oscillating charge of the carrier results in a step-like response in cellular uptake of the DNA-complex with fluctuating $\mathrm{pH}$.

were incubated at $\mathrm{pH} 6.8$ (Fig. 1d). After changing to $\mathrm{pH}$ 7.4, fluorescence intensity was maintained at a comparable level. Appreciably little fluorescence was measured for cells only exposed to $\mathrm{pH} 7.4$ (in stark contrast to the $\mathrm{bPEI}_{25 \mathrm{~K}} / \mathrm{DNA}$-complex), indicating the necessity for $\mathrm{pH}$-triggered charge reversal of the DNA-complex for cellular uptake. It is important to note that this result indicates that delivery occurs due to polymer-mediated cellular uptake dependent on the extracellular environment. In addition, the intensity of fluorescent signals of treated cells continuously increased for those exposed to the DNA-complex incubated in the slightly acidic environment ( $\mathrm{pH}$ 6.8). Switchable release from the carrier is indicated by the data for alternating between $\mathrm{pH} 6.8$ and 7.4, exemplified by the data points between 60 and 90 min when $\mathrm{pH}$ reverted to 7.4 (purple diamonds). Emphasis of the critical need for carrier design is presented in the data showing that for all the treatments of the $\mathrm{bPEI}_{25 \mathrm{~K}} / \mathrm{DNA}$-complex, the fluorescent intensities of cells in both $\mathrm{pH}$ conditions achieved consistently similar levels, indicating non-pH-mediated cellular uptake of $\mathrm{bPEI}_{25 \mathrm{~K}} / \mathrm{DNA}$-complex. Consistent with previous observations, these data indicate that the positively charged complex facilitates an association with the anionic cell membrane ${ }^{24,25}$. Exposure to fetal bovine serum (FBS) was shown, herein, to have the comparable fluorescent intensity of cellular uptake of test complexes in treated cells (Supplementary Fig. 4).

Effect of $\mathrm{pH}$ on polymeric transfection of p53 and KillerRed. We quantified the efficacy of p53 expression through the DNA- complex or $\mathrm{bPEI}_{25 \mathrm{~K}} / \mathrm{DNA}$-complex in an additional incubation of $48 \mathrm{~h}$ by the enzyme linked immunosorbent assay (ELISA) using the p53-deficient H1299 cells (Fig. 2a). The p53 expression observed in the DNA-complex-transfected cells increased noticeably with the acidic environment. The $\mathrm{p} 53$ expression with $\mathrm{bPEI}_{25 \mathrm{~K}} / \mathrm{DNA}$-complex had no significant difference between $\mathrm{pH}$ 7.4 or 6.8 , evidencing the lack of $\mathrm{pH}$-responsive uptake of the $\mathrm{bPEI}_{25 \mathrm{~K}} / \mathrm{DNA}$-complex. In the treatment with DNA-complex at $\mathrm{pH}$ 7.4, no labelling resulting from apoptosis signalling indicated by TUNEL (terminal deoxynucleotidyl transferase (TdT) dUTP nick-end labelling) assay was observed, implying that the positive immunocytochemical response was not caused by endogenous cell peroxidases. However, $\mathrm{bPEI}_{25 \mathrm{~K}}$ can induce dose-dependent damage to cell membranes and subsequently leads to the initiation of apoptosis due to a high charge density, indicated by the cytotoxic effect for the $\mathrm{bPEI}_{25 \mathrm{~K}} / \mathrm{DNA}$-complex ${ }^{26}$.

In addition, flow cytometry quantified fluorescence intensity and $\mathrm{TE}$ of KillerRed-positive cells. The $\mathrm{bPEI}_{25 \mathrm{~K}} / \mathrm{DNA}$-complex showed high intensities of KillerRed-positive cells at each pH (Fig. 2b). In the DNA-complex-transfected cells, the fluorescence intensity and TE of the cells exhibited significantly different efficiencies of KillerRed-positive cells between the different $\mathrm{pH}$ values. These changes of monitoring KillerRed were imaged on a confocal microscopy (Fig. 2b). We further chose the irradiation time of 20 min for optimized ROS generation, KillerRed phototoxicity and KillerRed-mediated apoptosis for following studies (Fig. 3a,b). We also observed the ROS generated in the photoactivated KillerRedexpressed cells at $\mathrm{pH} 6.8$ or 7.4 visualized with CellROX staining 
a

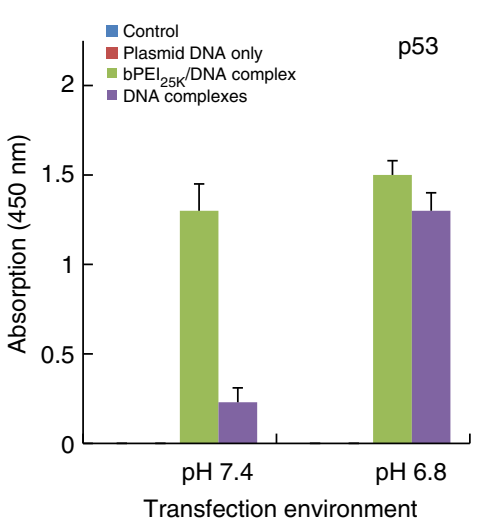

C

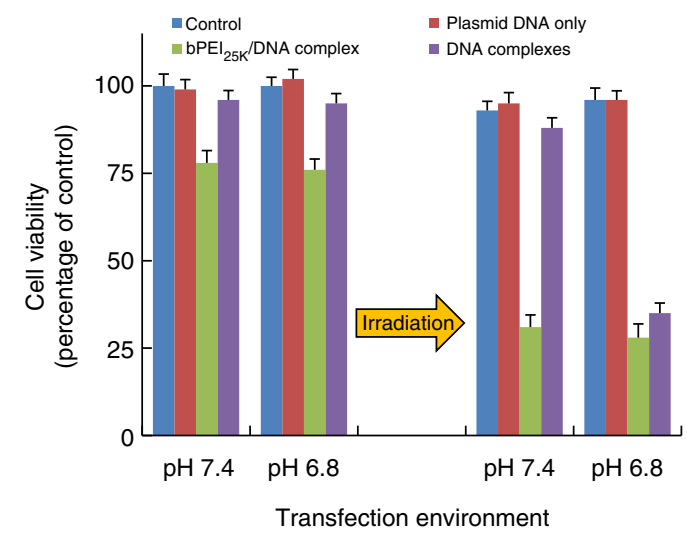

b
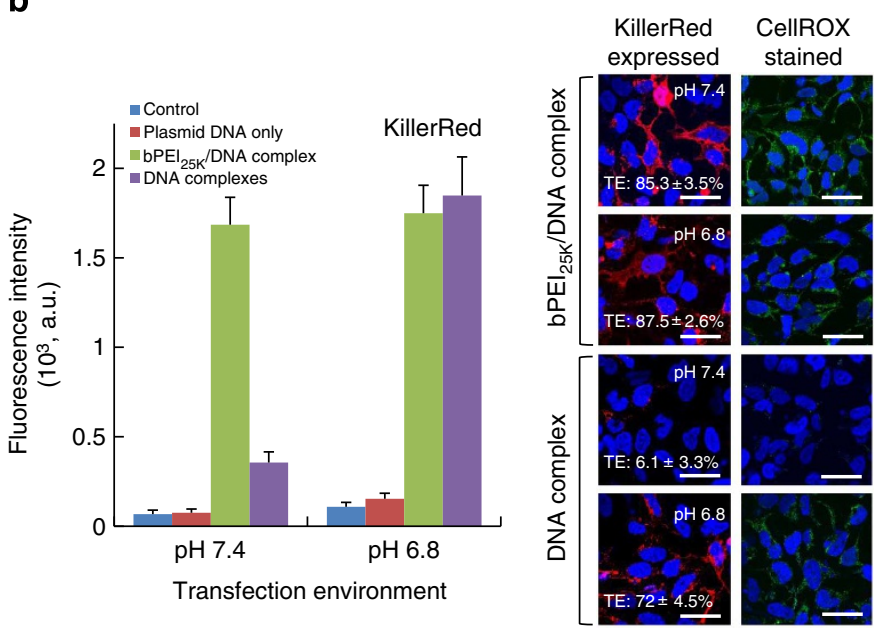

d
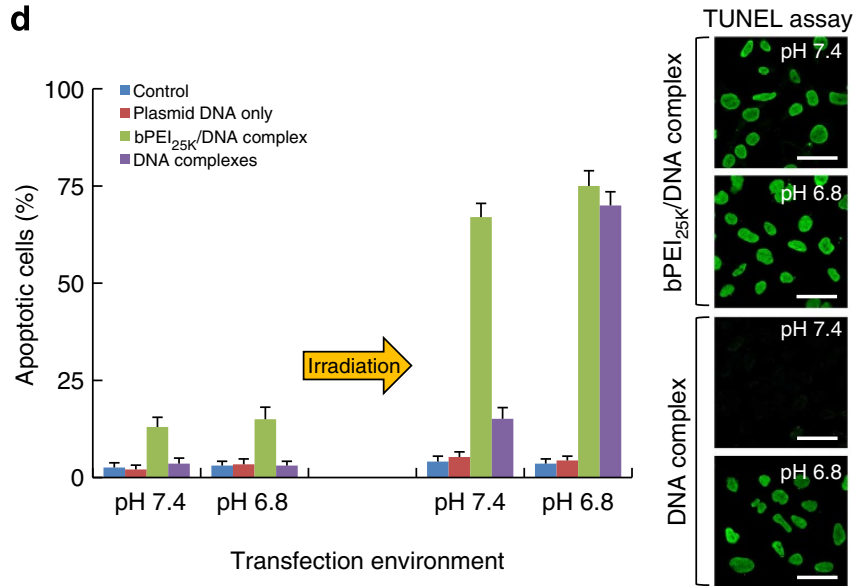

Figure 2 | In vitro gene expression at pH 7.4 and $\mathbf{6 . 8}$ transfection. (a,b) The protein expression of p53 (a) and KillerRed (b) via DNA-complex or $\mathrm{bPEI}_{25 \mathrm{~K}}$ /DNA-complex delivery in $\mathrm{H} 1299$ cells in culture medium at $\mathrm{pH} 7.4$ or $6.8,48 \mathrm{~h}$ post transfection. p53 protein in cell lysates was measured by ELISA assay using $450 \mathrm{~nm}$ absorbance for quantification. Confocal images showing the p53-mediated apoptosis was observed by TUNEL assay using a fluorescein. The fluorescence intensity and TE of KillerRed-positive cells were analysed by flow cytometry. Confocal images show KillerRed expression or ROS generation mediated by KillerRed photoactiviation was observed in transfected cells, in which the CellRox green dye and DAPI stains identify ROS and nuclei, taken $20 \mathrm{~min}$ exposure $\left(593 \mathrm{~nm}, 100 \mathrm{~mW} \mathrm{~cm}^{-2}\right.$ ). (c) Cell viability of transgene-expressing cells incubated at pH 7.4 or 6.8 with and without irradiation with a yellow laser, determined by the MTS assay. (d) Percentages of apoptotic cells stained by TUNEL assay incubated after a light exposure of $20 \mathrm{~min}$ and different $\mathrm{pH}$ values, analysed by flow cytometry. Confocal images show that the apoptotic cells were observed by TUNEL assay. All results show mean of measurements conducted in triplicate \pm s.d. Scale bar, $50 \mu \mathrm{m}$.

(Fig. 2b). In the cells treated with the DNA-complex, the slightly acidic $\mathrm{pH}$ had a positive effect on the ROS generation with a pronounced difference occurring between the $\mathrm{pH}$ values. The transgene was expressed as a function of time with a maximum intensity observed at $\sim 48 \mathrm{~h}$ before subsequent decrease (Fig. $3 \mathrm{c}$ ). The result implies the photocytotoxicity towards cells reduces over reasonable time frames, reaching $\sim 40 \%$ of the peak concentration 7 days after transfection, and consistent with our expectations for the time frame of degradation and plasmid gene expression. Significant increase in p53 and KillerRed expression via the DNAcomplex incubated at different $\mathrm{pH}$ values also corroborated our findings, indicating greater cellular uptake triggered with decreased environment $\mathrm{pH}$.

Viability of the treated cells was determined by the 3-(4,5dimethylthiazol-2-yl)-5-(3-carboxymethoxyphenyl)-2-(4-sulfophenyl)-2H-tetrazolium, inner salt (MTS) assay, and cells with no treatment of transfection served as a control group. According to Fig. 2c, with light irradiation alone, no significant photocytotoxicity to the control cells incubated at $\mathrm{pH} 7.4$ or $\mathrm{pH} 6.8$ was observed within 20 min of light exposure. Conversely, upon light irradiation, the viability of the cells treated with the DNAcomplex declined markedly with a strong $\mathrm{pH}$ dependence, presumably due to an efficient elevation in their cellular uptake levels (Fig. 1d) and gene expression (Fig. 2a,b). Compared with the DNA-complex, the $\mathrm{bPEI}_{25 \mathrm{~K}} / \mathrm{DNA}$-complex-mediated cell viability showed no significant difference between $\mathrm{pH} 7.4$ or 6.8 after light irradiation.

KillerRed-mediated ROS production has been reported to cause a variety of oxidative damages to lipids and cellular organs ${ }^{16}$, leading to an enhancement of p53-mediated apoptosis response in p53 gene-transfected cells ${ }^{9,11,14}$. To determine whether cell death in the photoactivated cells could be explained via the induction of apoptosis, we used the TUNEL assay to characterize apoptosis. Before light irradiation, no significant TUNEL fluorescence in the control cells and DNAcomplex-treated cells was observed (Fig. 2d). Conversely, there was obvious apoptosis $(\sim 13-15 \%)$ in the $\mathrm{bPEI}_{25 \mathrm{~K}} / \mathrm{DNA}$ complex-transfected cells, suggesting that the effect of $\mathrm{bPEI}_{25 \mathrm{~K}}$ 
a

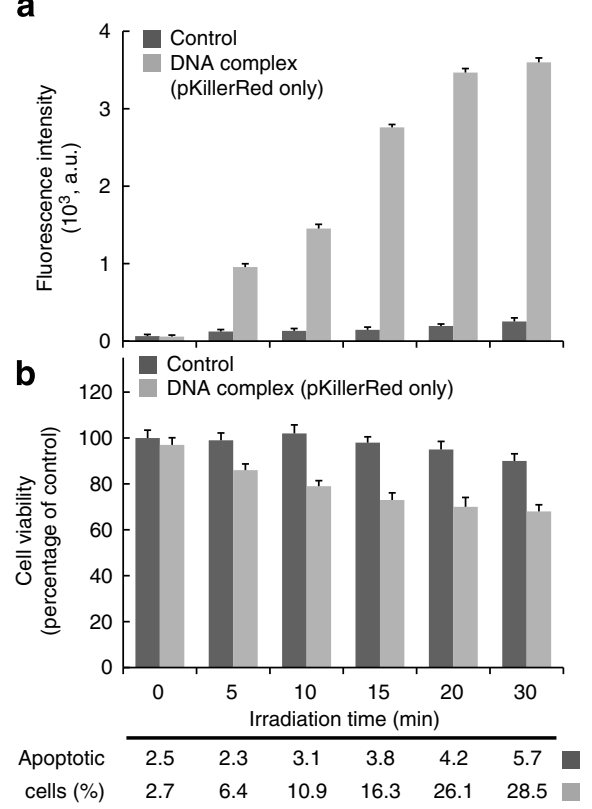

C

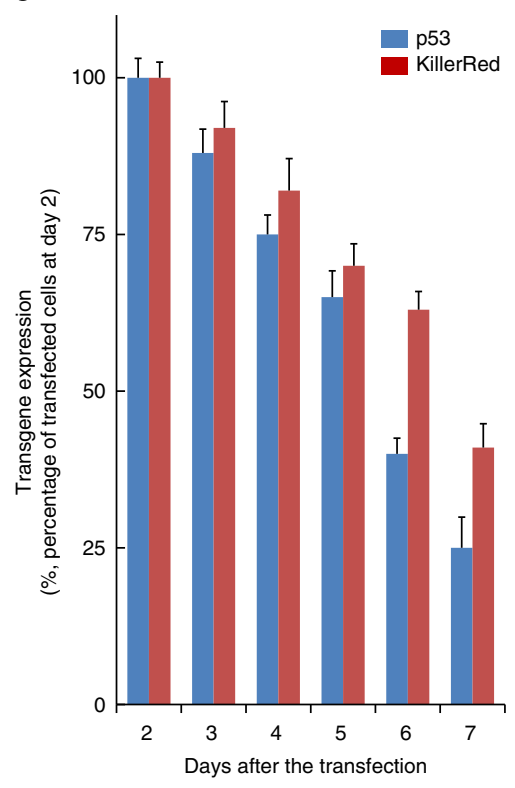

Figure 3 | KillerRed photoactivation and degradable transgene expression. (a) Fluorescence intensity of ROS generation by KillerRed-positive cells incubated at different light exposure time periods $\left(593 \mathrm{~nm}, 100 \mathrm{~mW} \mathrm{~cm}^{-2}\right.$ ), analysed by flow cytometry. The cells were transfected with DNA-complexes containing only plasmid DNA of KillerRed at pH 6.8. Results show the mean of the measurements conducted in triplicate \pm s.d. (b) Results of the viability and apoptosis of KillerRed-positive cells incubated at light exposure time points determined by the MTS assay and TUNEL assay. Results show the mean of the measurements conducted in triplicate \pm s.d. The untreated cells were used as a control. (c) Kinetics of gene expression in cells transfected with the DNA-complex (weight ratio of $0.5 / 1 / 1$ ) at $\mathrm{pH} 6.8$. Results show mean of measurements conducted in triplicate \pm s.d.

toxicity has induced apoptosis ${ }^{26}$. However, following the light exposure treatment, an average of $67 \%$ of cells transfected with $\mathrm{bPEI}_{25 \mathrm{~K}} / \mathrm{DNA}$-complex at $\mathrm{pH} 7.4$ were apoptotic, whereas only $15 \%$ of cells transfected with DNA-complex were apoptotic. However, this rate increased dramatically to $\sim 70 \%$ after incubation in the slightly acidic environment ( $\mathrm{pH}$ 6.8). These data further demonstrate that p53-mediated apoptosis here is collectively determined by $\mathrm{pH}$-dependent uptake, transfection and KillerRed photoactivation.

Genetic PDT after a single administration. To validate these data in vivo we administered carriers in an athymic BALB/c nude mouse with aggressive subcutaneous H1299 cells tumour model. Tumour excised after tail vein injection were analysed for $\mathrm{p} 53$ expression by PCR analysis. All the tumours from the mice injected with formulations containing $\mathrm{bPEI}_{25 \mathrm{~K}} / \mathrm{DNA}$-complex and DNA-complex expressed p53 while the PBS and plasmid DNA only controls did not. Remarkable expression of p53 and KillerRed was achieved when the DNA-complex was administered systemically via tail vein injection (Fig. 4a). The expression in tumour of mice $48 \mathrm{~h}$ after treatment with the DNA-complex measured $>2$ times greater compared with tumour from animals injected with the $\mathrm{bPEI}_{25 \mathrm{~K}} / \mathrm{DNA}$-complex. In addition, the percentage of KillerRed-positive cells as TE of DNA-complex in a single administration was over two times greater compared with $\mathrm{bPEI}_{25 \mathrm{~K}} / \mathrm{DNA}$-complex (Supplementary Fig. 5). Furthermore, it was equally important to validate the p53 or KillerRed expression in the tumour using immunoblot analyses. These results indicated that the $\mathrm{pH}$-sensitive DNA-complex can mediate more specific and efficient gene expression (Fig. 4b). These data imply successful passive delivery of the DNA-complex to tumour site where inherent enhanced permeation and retention effect coupled with acidic microenvironment results in cellular uptake and localized, highly efficient gene transfection.
The advantages of this DNA-complex in tumour acidityinitiated plasmid DNA delivery can potentially enhance the efficiency of DNA transfection in cancer therapies within a clinical domain. Towards evaluating the therapeutic potential of the $\mathrm{pH}$-triggered transfection of p53 and KillerRed, we subsequently studied tumour growth suppression after a single delivery with the $\mathrm{bPEI}_{25 \mathrm{~K}} / \mathrm{DNA}$-complex or DNA-complex after tail vein administration. We compared four groups of mice injected with different formulations after tail vein injection. Laser light passed by an optical fibre (Supplementary Fig. 6a) was administered to the tumour from the 2 nd day for 20 min every day up to day 6 after formulation injection, relevant to the period for abatement of transgene expression following cell incubation (Fig. 3c). Body weights remained stable over the treatment periods and were similar to those of control animals (Supplementary Fig. 6b). After tail vein injection, it was observed that the DNA-complex was most effective in suppressing the established tumour volumes within a 72-h time period (Fig. 4c). As shown in other polymeric systems, tumour growth suppression stops and tumour progressively regrow after transgene p53 expression decreases ${ }^{27}$. No tumour growth suppression was observed when naked plasmid DNAs or PBS were administered by tail vein injection, presumably due to degradation by serum nucleases while in circulation. The median survival in animals treated with PBS, plasmid DNA or $\mathrm{bPEI}_{25 \mathrm{~K}} / \mathrm{DNA}$-complex was 28,30 and 45 days, respectively (Fig. 4d). Treatment with DNA-complex increased the median survival out to 68 days, demonstrating significant antitumour activity in vivo. In the biodistribution of transgene expression, DNA-complex targeted gene expression in tumour achieved expression that is significantly greater than that in the lung and liver (Fig. 4e,f). When delivered in vivo, $\mathrm{bPEI}_{25 \mathrm{~K}} / \mathrm{DNA}-$ complex preferentially accumulated in the lung ${ }^{28}$, similar to cationic liposomes ${ }^{29}$. In contrast, absolute expression in tumour from the DNA-complex was over 1.5 times greater than $\mathrm{bPEI}_{25 \mathrm{~K}} /$ DNA-complexes. Expression in tumour relative to lung tissue was 


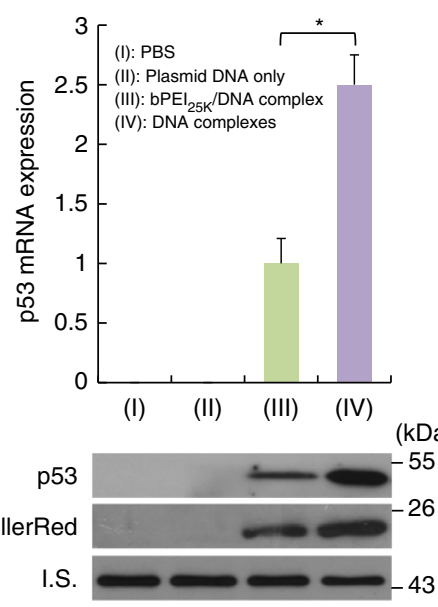

C

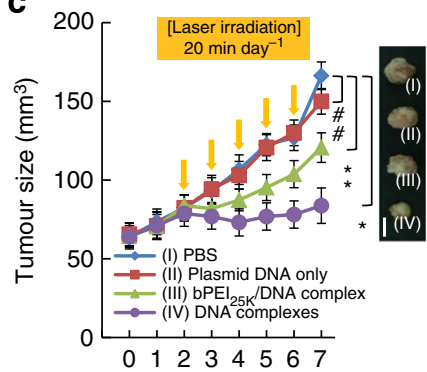

Days after the treatment

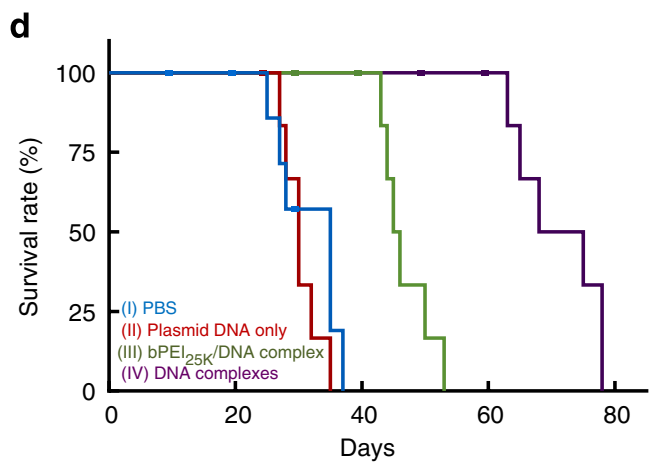

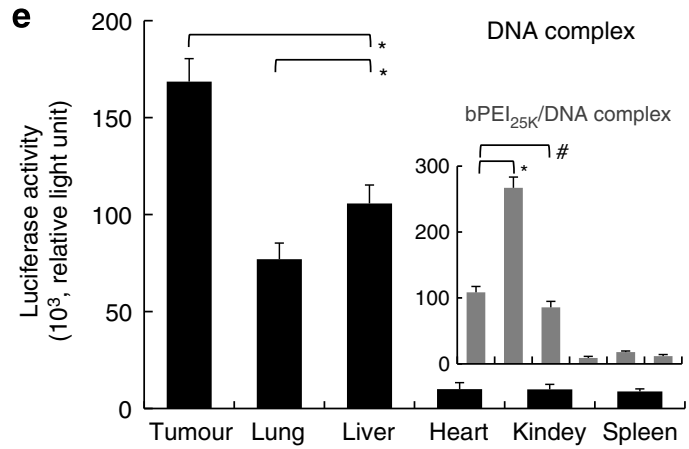

f

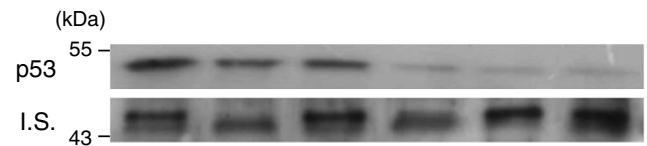

g

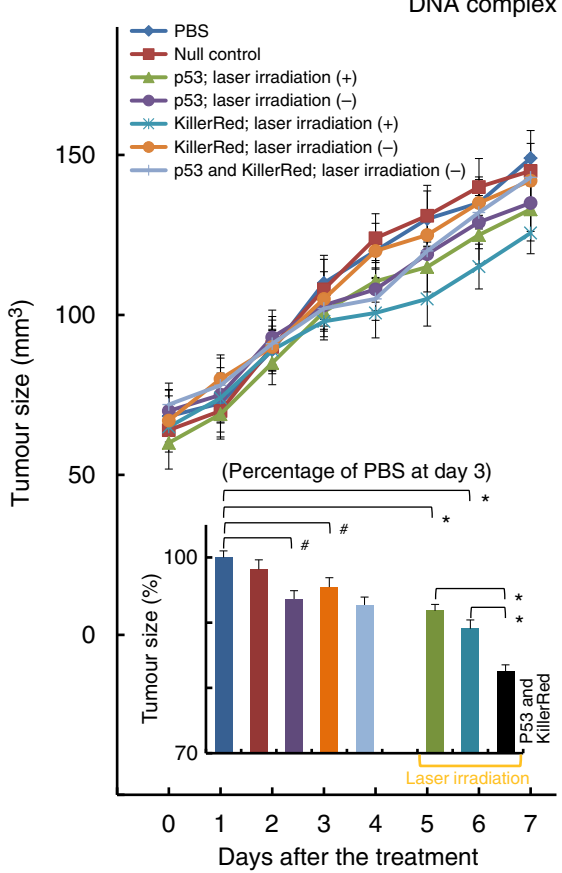

Figure 4 | Gene expression in an aggressive $\mathbf{H 1 2 9 9}$ mouse-tumour model after a single administration. (a) The p53 mRNA expression after tail vein injection; comparing PBS, plasmid DNA only, bPEI $25 \mathrm{~K} / \mathrm{DNA}$-complex and DNA-complex $48 \mathrm{~h}$ post injection $\left({ }^{\star} P<0.00015\right.$; based on a two-tailed $t$-test, assuming unequal variances). Representative fluorescence images of excised tumour from mice $48 \mathrm{~h}$ after tail vein injection. Scale bar, $2 \mathrm{~mm}$. The percentage of KillerRed-positive cells as TE was measured by flow cytometry. (b) Protein levels in tumour 2 days after tail vein injection of various complex formulations containing $10 \mu \mathrm{g}$ pCMV-p53 and $10 \mu \mathrm{g}$ pKillerRed-mem. Western blot analysis was performed using anti-p53 and KillerRed antibodies. $\beta$-actin protein was used as an internal standard. Total mRNA was isolated and determined for p53 by quantitative real-time reverse-transcription PCR analysis. (c) Effect of $\mathrm{pH}$-targeting and control complexes on tumour volumes by tail vein injection. Mice were injected with various complex formulations and $\mathrm{H} 1299$ subcutaneous tumour volumes were measured $\left({ }^{\star} P<0.00015 ;{ }^{\star \star} P=0.013\right.$; ${ }^{\# \#} P>0.1$; based on a two-tailed $t$-test, assuming unequal variances).

Representative samples of $\mathrm{H} 1299$ tumours excised on day 8 after a single treatment administration. Scale bar $=5 \mathrm{~mm}$. (d) Kaplan-Meier survival curve of mice treated with single doses by tail vein injection (e) Biodistribution of reporter expression after tail vein injection. Luciferase biodistribution at $48 \mathrm{~h}$ after injection was studied for DNA-complex or $\mathrm{bPEI}_{25 \mathrm{~K}} / \mathrm{DNA}$-complex containing $20 \mu \mathrm{g} \mathrm{pCMV-luciferase}\left({ }^{\star} P<0.005\right.$; ${ }^{*} P=0.11$; based on a two-tailed $t$-test, assuming unequal variances). Inset shows the data of bPEI ${ }_{25 \mathrm{~K}} / \mathrm{DNA}$-complex. (f) Protein levels of p53 in tumour and organs 2 days after tail vein injection. (g) Bystander effect on $\mathrm{H} 1299$ subcutaneous tumour volumes by tail vein injection of various complex formulations. Inset shows a zoomed-in view of the same data. Tumour size is given as the percentage of tumour volume $\left(\mathrm{mm}^{3}\right)$ after treatment for 3 days, compared against the PBS treatment $\left({ }^{\star} P<0.005\right.$; ${ }^{\#} P<0.05$; based on a two-tailed $t$-test, assuming unequal variances). All results show mean of measurements conducted in sextuplicate \pm s.d.

improved by $>5$ fold, resulting in a dominance of specific delivery (Supplementary Fig. 7).

Bystander effect. To assess the roles of p53 and KillerRed independently in the suppression of tumour growth, mice were tail vein injected with individual complex formulation with or without the treatment of laser irradiation (Fig. 4g). The DNA-complex containing null control did not significantly alter tumour growth. Interestingly, the DNA-complex containing KillerRed with light exposure treatment had a slight effect on the pattern of tumour size due to ROS formation by KillerRed. Data for p53 are 
consistent with the previous finding that $\mathrm{p} 53$ replenishment leads to tumour regression due to 53 protein stabilization and activation by oncogenic stress ${ }^{30}$. The DNA-complex containing both p53 and KillerRed conspicuously retarded tumour growth with the 20-min irradiation regimen. While DNA-complex generated a transgene expression in other organs (Fig. 4e), ROS generation is confined to the transgene expression, significantly impacting tumour tissue. $\mathrm{bPEI}_{25 \mathrm{~K}} / \mathrm{DNA}$-complex also achieved similar tumour suppressive activity (Supplementary Fig. 8), but the biodistribution study shows that $\mathrm{bPEI}_{25 \mathrm{~K}} / \mathrm{DNA}$-complex accumulated 2.5 times greater in the lung than in the tumour site (Fig. 4e, grey inset). These results suggest that $\mathrm{bPEI}_{25 \mathrm{~K}} / \mathrm{DNA}$ complex suffers from significant leakage and it therefore gives poor control for preferential tumour delivery compared with the DNA-complex. Although the result shows that both the mechanisms contributed to the retardation of tumour growth, the tumour growth suppression is significantly greater when p 53 and KillerRed are used in conjunction with laser irradiation.

Comparison of delivery routes. We further assessed p53 and KillerRed gene expression after intratumoural and intramuscular injection to compare the delivery approach and environment $\mathrm{pH}$ in vivo (Fig. 5a,b). Intratumoural injection was evaluated for a direct comparison of the complex in vivo. Intratumoural versus muscular environments demonstrates an environmental response, rather than a greater response due to vascular leakiness within the tumour. No significant difference was observed between tissues for the $\mathrm{bPEI}_{25 \mathrm{~K}} / \mathrm{DNA}$-complex. For the DNAcomplex, however, there was $\sim 4.1$-fold increase in gene expression of p53 in the tumour site compared with intramuscular sites. Direct injection into the tumour also had slightly improved effect over systemic delivery (Fig. 5c). Body weights remained stable over the treatment periods compared with PBS (Fig. 5d). Again, treatment with only plasmid DNAs of pCMVp53 and pKillerRed-mem did not demonstrate any tumour growth suppression in comparison with PBS. Direct delivery of the DNA-complex or $\mathrm{bPEI}_{25 \mathrm{~K}} / \mathrm{DNA}$-complex both suppressed tumour growth in the murine model and significantly reduced tumour volume. The tumour inhibitory effect by intratumoural injection demonstrates that the DNA-complex is responsive to the tumoural environment, that is, the lowered $\mathrm{pH}$ which enables gene release, rather than being a pseudo-targeted therapy by vascular leakiness to the tumour site. Taken together, these findings convincingly demonstrate that the DNA-complex developed here effectively suppresses tumour growth through highly $\mathrm{pH}$-sensitive, triggered cellular uptake and transfection of plasmid DNA in the tumour in vivo.

\section{Discussion}

PDT has broad and major application and requires the use and development of sensitizing agents ${ }^{17,31-39}$. PDT can be applied to a large number of cancer types such as $\operatorname{skin}^{31}$, head and neck ${ }^{32}$, a

Direct injection

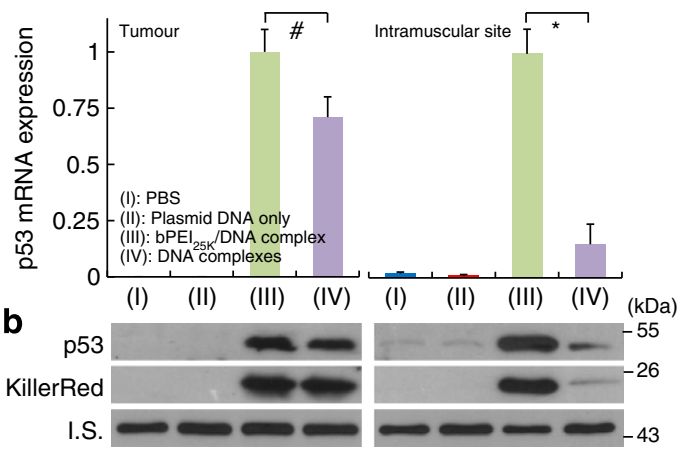

d

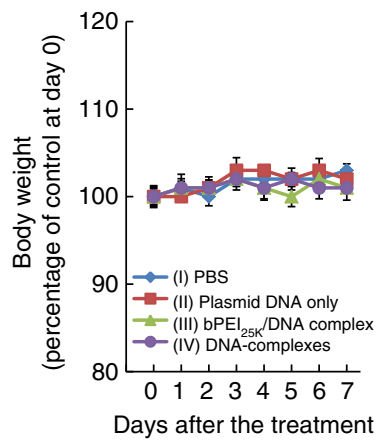

C

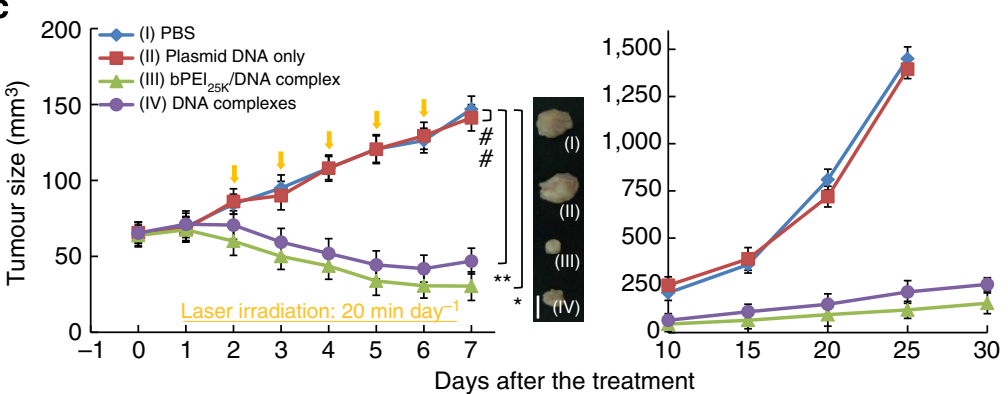

Figure 5 | Gene expression and tumour size after a single administration by direct injection. (a) The p53 mRNA expression after direct injection; comparing PBS, plasmid DNA only, bPEI25K/DNA-complex and DNA-complex 48 h post injection ( ${ }^{\star} P<0.00015$; ${ }^{\#} P=0.01$; based on a two-tailed $t$-test, assuming unequal variances). Results show the mean of the measurements conducted in sextuplicate \pm s.d. (b) Protein levels of p53 and KillerRed in tumour 2 days after the direct injection of various complex formulations containing $10 \mu \mathrm{g}$ pCMV-p53 and $10 \mu \mathrm{g}$ pKillerRed-mem via the four delivery methods. Whole-tumour lysates were extracted and western blot analysis was performed using anti-p53 and KillerRed antibodies. $\beta$-actin protein was used as an internal standard. Total mRNA was isolated and determined for p53 by quantitative real-time reverse-transcription PCR analysis. (c) Effect of pHtargeting and control complexes on tumour volumes by direct injection. Mice were injected with various complex formulations and $\mathrm{H} 1299$ subcutaneous tumour volumes were measured $\left({ }^{\star} P<0.00015 ;{ }^{\star \star} P=0.013 ;{ }^{\# \#} P>0.1\right.$; ; based on a two-tailed $t$-test, assuming unequal variances). Right panel: representative samples of $\mathrm{H} 1299$ tumours excised on day 8 after a single treatment administration. Scale bar, $5 \mathrm{~mm}$. All results show the mean of the measurements conducted in sextuplicate \pm s.d. (d) Body weight of mice over time in response to the treatments of various complex formulations by direct injection. Results show mean of measurements conducted in sextuplicate \pm s.d. 
bladder ${ }^{33}$, liver cancer $^{34}$, pancreatic cancer $^{35}$, oesophageal cancer $^{36}$ and prostate ${ }^{17}$. Further opportunities exist in preserving mucosal linings and alveoli, which suffer greatly during radiation therapy, in treatment of mouth and lung cancers, respectively. The non-ionizing nature of the radiation also allows for indiscriminate irradiation of tissues, and lesions at an early stage may be treated where surgery is preferred to be avoided or not an option. Specific to lung cancer, the U.S. Food and Drug Administration approved photodynamic therapy for the treatment of NSCLC as oncologists and surgeons seek additional tools in both its curative and palliative treatment ${ }^{37,38}$. It is important to note that therapies against NSCLC are multimodal and for advanced tumour often intend to render tumour operable for resection; such as by rendering lungs sufficient function for a patient to undergo pneumonectomy or upgraded to only requiring lobectomy. In this regard, a precise therapeutic regimen is administered to suppress growth and enable surgery. In addition, PDT for NSCLC has shown excellent palliative application significantly improving quality of life in the final months ${ }^{39}$. In this latter case, PDT is not applied with curative intent.

Furthermore, KillerRed can serve as a surrogate end point in regard to radiosensitization studies. Such studies can be conducted with relative ease with well-defined irradiation volumes and do not require the use of complex apparatus, dose planning and model development for irradiation experiments, for example with $\mathrm{MeV}$ accelerators which would struggle to deliver quantifiable, well-defined doses or shapes to a mouse model ${ }^{40}$.

In conclusion, a $\mathrm{pH}$-responsive charge reversal polymeric complex prepared by bPEI and the biodegradable poly(PEGHis $_{0.5}$-PEG-Glu ${ }_{0.5}$ ) copolymer, was employed to deliver both plasmid DNAs of p53 and KillerRed photosensitizer into cancer cells. We have achieved efficient transfection in tumour from systemic circulation with a switchable $\mathrm{pH}$-responsive complex triggered by tumour acidosis. The DNA-complex has reversible zeta potential switching between $\mathrm{pH} 7.4$ and 6.8 due to the protonation of amino groups. The unique behaviour of the DNAcomplex was used to demonstrate the $\mathrm{pH}$-dependent cellular uptake and transfection in the physiologically relevant $\mathrm{pH}$ range in vivo. Future development of this material could involve changing the hydrophobicity of the copolymer to load both hydrophobic and hydrophilic chemotherapeutic drugs. Furthermore, the complexes can be loaded with multiple guest molecules, reactants or drugs for dual/multiple delivery applications. Such a flexible modality adds greater potential to overcoming interindividual variability in therapeutic response with improved specificity.

\section{Methods}

Materials. $\beta$-Glutamic acid hydrochloride and dimethyl sulfoxide (DMSO) were purchased from Fluka (Buchs, Switzerland). L-Histidine dihydrochloride, diethyl ether, DAPI (4',6-diamidino-2-phenyindole, dilactate) and PBS were purchased from Sigma Co. (St Louis, MO). Poly(ethylene glycol) (PEG) diacrylate $(\mathrm{Mn}=258$, density $\left.=1.11 \mathrm{~g} \mathrm{ml}^{-1}\right)$ and branched polyethyleneimine $\left(\mathrm{bPEI}_{25 \mathrm{~K}}, \mathrm{Mw}=25,000\right)$ were purchased form Aldrich (Milwaukee, MI). Plasmid DNA of pCMV vector (pcDNA 3.1) as a null control was purchased from Invitrogen (Carlsbad, CA, USA). Plasmid DNAs of pGL3, pCMV-p53 and pKillerRed-mem were purchased from Promega (Madison, WI, USA), Clontech Laboratories (Mountain View, CA) and Evrogen JSC (Moscow, Russia), respectively. For the preparation of fluorescent-labelled plasmid DNA, pCMV-p53 and pKillerRed-mem stocks were labelled with fluorescein as a fluorescent dye using a Label IT Nucleic Acid Labeling Kit (Mirus Bio, Madison, WI).

Synthesis and characterization of poly(PEG-His . $_{0.5}$-PEG-Glu ${ }_{0.5}$. Poly(PEG$\mathrm{His}_{0.5}$-PEG-Glu ${ }_{0.5}$ ) was prepared according to the protocols for copolymerization (Supplementary Fig. 1) ${ }^{24}$. In a typical experiment using a parallel synthesizer connected to a vacuum line with the vacuum controlled by a digital vacuum controller, reaction mixtures were prepared, which contained L-histidine dihydrochloride $(50.0 \mathrm{mg}, 0.219 \mathrm{mmol}), \beta$-glutamic acid hydrochloride $(40.2 \mathrm{mg}$,
$0.219 \mathrm{mmol}$ ) in DMSO solvent, and the mixtures were then stirred at $25^{\circ} \mathrm{C}$ for $1 \mathrm{~h}$ to achieve a homogeneous solution. A PEG diacrylate $(101.5 \mu \mathrm{l}, 0.437 \mathrm{mmol})$ was added dropwise to the mixtures, and then heated in a constant temperature oil bath at $65-75^{\circ} \mathrm{C}$ for $120 \mathrm{~h}$. The yellow colloidal copolymer ( $45 \%$ yield) was isolated and purified by washing with diethyl ether $(10 \mathrm{ml})$ three times and dried at $40{ }^{\circ} \mathrm{C}$ under high vacuum $(1.0 \mathrm{~mm} \mathrm{Hg})$ for $16 \mathrm{~h}$.The designated functional groups and copolymer structure of poly(PEG-His ${ }_{0.5}$-PEG-Glu ${ }_{0.5}$ ) were confirmed by ${ }^{1} \mathrm{H}$ NMR and ${ }^{13} \mathrm{C} \mathrm{NMR}$ spectra based on DMSO- ${ }_{\mathrm{d} 6}(99.8 \%)$ as a solvent ${ }^{24}$. The molecular weight

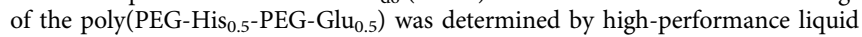
chromatography/gel permeation chromatography analysis (HPLC/GPC, Waters model LC-2410). Tetrahydrofuran was used as an eluent in HPLC/GPC at the flow rate of $1.0 \mathrm{ml} \mathrm{min}^{-1}$. The weight- and number-average molecular weights (Mw and $\mathrm{Mn}$, respectively) were calibrated using polystyrene as a reference. The

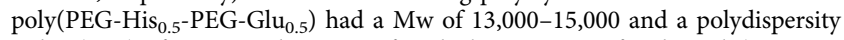
index (PDI) of 1.8-2.0. The curve of acid-base titration for the poly(PEG-His ${ }_{0.5}$ PEG-Glu ${ }_{0.5}$ ) was used to empirically estimate $\mathrm{pH}$ sensitivity and to confirm its buffering capacity from $\mathrm{pH} 10.8$ to $\mathrm{pH} 3.5$.

Preparation of DNA-complexes. Test DNA-complexes at various known weight ratios $(\mathrm{w} / \mathrm{w} / \mathrm{w})$ of $\mathrm{bPEI}_{25 \mathrm{~K}} / \mathrm{DNA} /$ poly$\left(\mathrm{PEG}-\mathrm{His}_{0.5}-\mathrm{PEG}-\mathrm{Glu}_{0.5}\right)$ and $\mathrm{bPEI}_{25 \mathrm{~K}} / \mathrm{DNA}$ complex were prepared by an electrostatic method in deionized water $(\mathrm{pH} 7.4$; refs 24,25). An aqueous solution of pCMV-p53 $(0.5 \mu \mathrm{g})$ and pKillerRed-mem $(0.5 \mu \mathrm{g})$ was mixed with an aqueous poly(PEG-His ${ }_{0.5}$-PEG-Glu ${ }_{0.5}$ ) solution at $1.0 \mu \mathrm{g}$ with a final volume of $100 \mu \mathrm{l}$. The DNA-complexes at various known weight ratios (w/w/ $\mathrm{w})$ of $\mathrm{bPEI}_{25 \mathrm{~K}} / \mathrm{DNA} /$ poly$\left(\mathrm{PEG}-\mathrm{His}_{0.5}-\mathrm{PEG}-\mathrm{Glu}_{0.5}\right)(0.25 / 1 / 1,0.5 / 1 / 1,1 / 1 / 1$ and $2 /$ $1 / 1$ ) were obtained on addition of the mixture solution, using a pipette, into an aqueous bPEI $_{25 \mathrm{~K}}\left(0.1 \mu \mathrm{g} \mu \mathrm{l}^{-1}\right)$ and then thoroughly mixed for 30-60 s by vortex mixing and left for at least $30 \mathrm{~min}$ at room temperature before measurements. In addition, the $\mathrm{bPEI}_{25 \mathrm{~K}} / \mathrm{DNA}$-complex at weight ratio (w/w) of $2 / 1$ was used as a standard control.

Characterization of DNA-complexes. The hydrodynamic diameter and the zeta potential measurements at different $\mathrm{pH}$ values $(7.4,7.2,7.0,6.8$ and 6.5$)$ were carried out using a Zetasizer Nano ZS (Malvern Instruments). The temperature for the measurement was kept at $25^{\circ} \mathrm{C}$. The concentration of the samples was $0.03 \%$ w/v. The $\mathrm{pH}$ value of the solutions was adjusted using $0.5 \mathrm{M}$ aqueous $\mathrm{HCl} / \mathrm{NaOH}$ solutions. A drop of the complex solution was allowed to air dry onto a Formvarcarbon-coated 200-mesh copper grid for transmission electron microscopy (JEOL JEM-2100F) analysis. Transmission electron microscopy images were then acquired on a JEOL-1010 microscope operating at an accelerating voltage of $100 \mathrm{kV}$

Cell culture and cytotoxicity of DNA-complexes. The human NSCLC cell line H1299 (CRL-5803, ATCC) was cultured in RPMI (Roswell Park Memorial Institute) 1640 medium with $10 \%$ FBS. Cells were cultured in a $37^{\circ} \mathrm{C}$ incubator with $5 \%$ $\mathrm{CO}_{2} .1 \times 10^{5} \mathrm{H} 1299$ cells were seeded in each of the wells of a 24 -well plate and fed with culture medium for $12 \mathrm{~h}$. The cells were then exposed to test DNA-complexes at different weight ratios and incubated at $\mathrm{pH} 7.4$ or $\mathrm{pH} 6.8$ for $24 \mathrm{~h}$. After $24 \mathrm{~h}$ incubation, the transfection media containing test samples were removed. In addition, the $\mathrm{bPEI}_{25 \mathrm{~K}} / \mathrm{DNA}$-complex was only incubated at $\mathrm{pH} 7.4$ or $\mathrm{pH} 6.8$ for $2 \mathrm{~h}$ and the culture medium was replaced. The CellTiter 96 AQueous one solution cell proliferation assay system (Promega, Madison, WI, USA) was used to determine the cell proliferation as per previously studies ${ }^{20,24,25}$. The optical density of formazan at $490 \mathrm{~nm}$ quantified the cell viability. The reagent contained a tetrazolium compound MTS and the reduction of MTS achieved by untreated cells was set at $100 \%$ and that of test cells was expressed as a percentage of untreated cells.

Transfection. H1299 cells were seeded in 24 -well plates at $1 \times 10^{5}$ cells per well and transfected the next day. Culture medium was removed and cells were rinsed twice with RPMI 1640 medium without FBS ( $\mathrm{pH} 7.4$ ). Cells were replenished with $1,000 \mu \mathrm{l}$ culture medium containing test complexes at a concentration of $1 \mu \mathrm{g}$ plasmid DNA per well.

Measurement of cellular uptake of DNA-complexes. To measure the cellular uptake of test complexes, we used the fluorescein-labelled plasmid DNA as the signal indicator. The measurement of cellular uptake was repeated for two cycles ( 30 min per cycle) of $\mathrm{pH}$ change between 7.4 and 6.8 when cells were transfected with test complexes. After a total of $2 \mathrm{~h}$ treatment, the transfection medium containing test samples was removed, the cells were rinsed twice with medium followed by analysis at different time points. In the control, the DNA-complexes or the $\mathrm{bPEI}_{25 \mathrm{~K}} / \mathrm{DNA}$-complex were incubated at only $\mathrm{pH} 7.4$ or 6.8 for $2 \mathrm{~h}$ transfection. Alternatively, we evaluated the cellular uptake of test samples in the transfection medium with $10 \%$ FBS at $\mathrm{pH} 7.4$ or 6.8 for $2 \mathrm{~h}$ transfection.

In vitro assays. The fluorescence intensity of cellular uptake using the fluoresceinlabelled plasmid DNA was quantitatively assessed by flow cytometry. Cells were 
detached by $0.025 \%$ trypsin and the suspensions were transferred to microtubes, fixed by $4 \%$ paraformaldehyde. The fluorescence intensity was determined with a flow cytometer (Beckman Coulter, Fullerton, CA, USA). Cells were appropriately gated by forward and side scatter and 10,000 events per sample were collected. The untreated cells were used as the negative control.

The p53 activities were determined in an additional $48 \mathrm{~h}$ post transfection. The quantitative detection of p53 protein level in cell lysates was measured by ELISA assay (Invitrogen p53 ELISA Kit, Camarillo, CA) and the absorbance of reaction reagent at $450 \mathrm{~nm}$ quantified the protein concentration using a spectrophotometer following the manufacturer's directions. The detection of p53-mediated apoptosis was observed using In Situ Cell Death Detection Kit, Fluorescein (Roche, Mannheim, Germany) as described by manufacturer. Cells were washed with PBS and then fixed with $4 \%$ paraformaldehyde, washed twice with PBS, resuspended in permeabilization solution ( $0.1 \%$ Triton X-100 and $0.1 \%$ Sodium citrate) for $15 \mathrm{~min}$ at $37^{\circ} \mathrm{C}$ and incubated with TUNEL reaction mixture for $60 \mathrm{~min}$ at $37^{\circ} \mathrm{C}$ in a humidified atmosphere in dark. After washing three times in PBS for $2 \mathrm{~min}$, the cells were analysed by a confocal microscope. The TUNEL-positive cells through p53-mediated apoptosis were further analysed using flow cytometry.

Alternatively, the transfected cells were analysed by flow cytometry (BD Bioscience, San Jose, CA, USA) equipped with a $561 \mathrm{~nm}$ argon laser for quantification of the fluorescence intensity and TE of KillerRed-positive cells. These cells were irradiated with yellow laser of $593 \mathrm{~nm}\left(100 \mathrm{~mW} \mathrm{~cm}^{-2}\right)$ for various irradiation periods to quantify the amount of ROS stained with CellROX Green Reagent (Invitrogen, Camarillo, CA), whereas the control was kept in darkness. The treated cells were stained by DAPI to label the cell nuclei. The transfected cells with or without irradiation at various time periods were quantified for cell viability by MTS assay or TUNEL assay. The reduction of MTS achieved by untreated cells was set at $100 \%$ and that of test cells was expressed as a percentage of untreated cells. We further chose the irradiation time of $20 \mathrm{~min}$ for optimized ROS generation and KillerRed phototoxicity for following studies (Fig. 3a,b). The kinetics of p53 or KillerRed expression was investigated by examining the time course of transgene expression in cells after transfection, using spectrophotometry or flow cytometry.

Mouse model. All procedures involving animals were permitted by Academia Sinica Institutional Animal Care and Utilization Committee (AS IACUC). Athymic $\mathrm{BALB} / \mathrm{c}$ nude mice (6-8 weeks old female) were provided by National Laboratory Animal Center (Taiwan). Mice were maintained in a controlled environment with a $12 \mathrm{~h} / 12 \mathrm{~h}$ light/dark cycle, housed in groups of five maximum and allowed food and water ad libitum. Cultured H1299 cells $\left(5 \times 10^{6}\right.$ cells in $100 \mu \mathrm{l}$ per mouse RPMI 1640 solution with 50\% Matrigel) were injected subcutaneously into the mice. The tumour xenograft formation was monitored until reaching $5 \mathrm{~mm}$ in size in one plane and the volume for each individual tumour was calculated by the formula $(\mathrm{V}=($ length $/ 2) \times($ width $) 2)$.

Mice study. The complex formulations (containing $10 \mu \mathrm{g}$ pCMV-p53 and $10 \mu \mathrm{g}$ pKillerRed-mem, $20 \mu \mathrm{g}$ pCMV-p53, $20 \mu \mathrm{g}$ pKillerRed-mem or $20 \mu \mathrm{g}$ pCMV vector of null control) were injected in a volume of $100 \mu \mathrm{l}$ via tail vein or directly into tumour of mice (athymic BALB/c nude mice with aggressive subcutaneous H1299 cells) by single injections. A yellow laser with $593 \mathrm{~nm}$ wavelength was used throughout this study. The light was delivered through an optical fibre and irradiated the tumour surface over a 6 -mm-diameter beam spot. Animals were treated with $100 \mathrm{~mW} \mathrm{~cm}^{-2}$ total irradiance, determined by measuring power (PM100A, Thorlabs, Germany) before and after illumination. The tip of the laser fibre was mounted above the tumour, perpendicular to the animal. This regimen was determined following initial optimization experiments. The laser treatment was administered to the tumour for 20 min every day for 5 days starting from the 2nd day after injection. Tumour size examination was conducted $24 \mathrm{~h}$ after the last treatment. Survival rate after tail vein injection was examined.

Biodistribution of reporter expression. Biodistribution of transgene expression after tail vein injection was evaluated. For examination of transgene expression in vivo, animals were injected with transfection complexes with $20 \mu \mathrm{g}$ pCMVluciferase, which was based on the luciferase gene from pGL3 cloned into pcDNA 3.1. Animals were killed at $48 \mathrm{~h}$ post injection. Organs were resected and homogenized in $250 \mathrm{~mm}$ Tris buffer, $\mathrm{pH}$ 7.5, using an IKA-homogenizer, frozen in liquid nitrogen and stored at $-80^{\circ} \mathrm{C}$. The tissue lysates were centrifuged at $14,000 \mathrm{~g}$ for $10 \mathrm{~min}$ at $4{ }^{\circ} \mathrm{C}$ to pelletise debris. Quantification of luciferase activity in the lysates has already been described in ref. 25 . The activity of luciferase was measured with the luciferase assay system (Promega, Madison, WI, USA) according to the manufacturer's protocols and with a 20/20n Luminometer (Turner Biosystems, Sunnyvale, CA, USA).

In vivo assays. The tumour xenografts from mice injected with DNA-complexes or $\mathrm{bPEI}_{25 \mathrm{~K}} / \mathrm{DNA}$-complex formulations at $48 \mathrm{~h}$ post injection were removed and immediately stored at $-80^{\circ} \mathrm{C}$. Total RNA was extracted from the homogenized tumour xenografts using RNeasy Plus Mini Kit (QIAGEN, CA, USA) and firststrand cDNA was synthesized with the Superscript III Reverse Transcriptase system (Invitrogen, CA, USA) according to the manufacturer's instructions. p53
CDNA was measured for quantitative real-time reverse-transcription PCR reaction analysis using the following sequences of primers of p53: $5^{\prime}$-TCTGGGACAGCCA AGTCTG- $3^{\prime}$ and 5'-CTTCCAGTGTGATGATGGT-3'. Reporter KillerRed expression in tumour xenografts was visualized by the Nikon ECLIPSE TS100-F fluorescence microscope and reporter simultaneously excited by yellow laser through an optical fibre. Furthermore, single cell suspensions from tumour xenografts were obtained using a disaggregation procedure that resulted in efficient tumour cell recovery. In this disaggregation procedure, tumour xenografts were digested by collagenases followed by mechanical disaggregation in a BD Medimachine System (BD Bioscience, San Jose, CA, USA). Subsequently, the percentage of KillerRed-positive cells as a TE was assessed by flow cytometry.

Tumour xenograft lysates were mixed with Laemmli loading buffer, boiled, separated by sodium dodecyl sulfate polyacrylamide gel electrophoresis and transferred to a nitrocellulose membrane. Subsequently, the immunoblot analyses were performed using antibodies specific to p53 and $\beta$-actin (Thermo Fisher Scientific, IL, USA) and KillerRed (Evrogen, Moscow, Russia). The signal was developed with enhanced chemiluminescence substrate (ECL, Thermo Fisher Scientific IL, USA) after incubation with appropriate secondary antibodies. Full western blot scans are provided in Supplementary Fig. 9.

Statistical analysis. Data are shown as the mean \pm s.d. for experiments performed in triplicate (in vitro studies) or sextuplicate (in vivo studies). In statistical significance testing, $P$ values were calculated using a two-tailed $t$-test, assuming unequal variances. The Kaplan-Meier survival analysis was used to estimate the overall survival curve.

\section{References}

1. Hollstein, M., Sidransky, D., Vogelstein, B. \& Harris, C. C. p53 mutations in human cancers. Science 253, 49-53 (1991).

2. Hoe, K. K., Verma, C. S. \& Lane, D. P. Drugging the p53 pathway: understanding the route to clinical efficacy. Nat. Rev. Drug Discov. 13, 217-236 (2014)

3. Brosh, R. \& Rotter, V. When mutants gain new powers: news from the mutant p53 field. Nat. Rev. Cancer 9, 701-713 (2009).

4. Prabha, S., Sharma, B. \& Labhasetwar, V. Inhibition of tumor angiogenesis and growth by nanoparticle-mediated p53 gene therapy in mice. Cancer Gene Ther. 19, 530-537 (2012).

5. Nemunaitis, J. et al. Biomarkers predict p53 gene therapy efficacy in recurrent squamous cell carcinoma of the head and neck. Clin. Cancer Res. 15, 7719-7725 (2009).

6. Senzer, N. et al. p53 therapy in a patient with Li-Fraumeni syndrome. Mol. Cancer Ther. 6, 1478-1482 (2007).

7. Senzer, N. et al. Phase I study of a systemically delivered p53 nanoparticle in advanced solid tumors. Mol. Ther. 21, 1096-1103 (2013).

8. Wang, S. P. et al. p53 controls cancer cell invasion by inducing the MDM2mediated degradation of Slug. Nat. Cell Biol. 11, 694-704 (2009).

9. Johnson, T. M., Yu, Z. X., Ferrans, V. J., Lowenstein, R. A. \& Finkel, T. Reactive oxygen species are downstream mediators of p53-dependent apoptosis. Proc. Natl Acad. Sci. USA 93, 11848-11852 (1996).

10. Seoane, J., Le, H. V. \& Massagué, J. Myc suppression of the p21(Cip1) Cdk inhibitor influences the outcome of the p53 response to DNA damage. Nature 419, 729-734 (2002).

11. Gogna, R., Madan, E., Kuppusamy, P. \& Pati, U. Reactive oxygen speciesmediated p53 core-domain modifications determine apoptotic or necrotic death in cancer cells. Antioxid. Redox Signal 16, 400-412 (2012).

12. Polyak, K., Xia, Y., Zweier, J. L., Kinzler, K. W. \& Vogelstein, B. A model for p53-induced apoptosis. Nature 389, 300-305 (1997).

13. Rivera, A. \& Maxwell, S. A. The p53-induced gene-6 (proline oxidase) mediates apoptosis through a calcineurin-dependent pathway. J. Biol. Chem. 280, 29346-29354 (2005).

14. Yousefi, A., Storm, G., Schiffelers, R. \& Mastrobattista, E. Trends in polymeric delivery of nucleic acids to tumors. J. Control. Release 170, 209-218 (2013).

15. Bulina, M. E. et al. A genetically encoded photosensitizer. Nat. Biotechnol. 24 95-99 (2006)

16. Liao, Z. X., Li, Y. C., Lu, H. M. \& Sung, H. W. A genetically-encoded KillerRed protein as an intrinsically generated photosensitizer for photodynamic therapy. Biomaterials 35, 500-508 (2014).

17. Moore, C. M., Pendse, D. \& Emberton, M. Photodynamic therapy for prostate cancer-a review of current status and future promise. Nat. Rev. Urol. 6, 18-30 (2009).

18. Chen, J. et al. In vitro and in vivo gene delivery using polyethyleniminepoly(hydroxyethyl glutamine) as a non-viral carrier. J. Control. Release 152(Suppl 1): e134-e136 (2011).

19. Liao, Z. X. et al. Enhancement of efficiencies of the cellular uptake and gene silencing of chitosan/siRNA complexes via the inclusion of a negatively charged poly(gamma-glutamic acid). Biomaterials 31, 8780-8788 (2010).

20. Lin, C. W. et al. Extracellular delivery of modified oligonucleotide and superparamagnetic iron oxide nanoparticles from a degradable hydrogel triggered by tumor acidosis. Biomaterials 34, 4387-4393 (2013). 
21. Yoo, J. W., Irvine, D. J., Discher, D. E. \& Mitragotri, S. Bio-inspired, bioengineered and biomimetic drug delivery carriers. Nat. Rev. Drug Discov. 10, 521-535 (2011).

22. Zeng, Y. F. et al. Controlled delivery of recombinant adeno-associated virus serotype 2 using $\mathrm{pH}$-sensitive poly(ethylene glycol)-poly-L-histidine hydrogels. Biomaterials 33, 9239-9245 (2012).

23. Helmlinger, G., Yuan, F., Dellian, M. \& Jain, R. K. Interstitial pH and pO2 gradients in solid tumors in vivo: high-resolution measurements reveal a lack of correlation. Nat. Med. 3, 177-182 (1997).

24. Tseng, S. J. et al. Switchable delivery of small interfering RNA using a negatively charged $\mathrm{pH}$-responsive polyethylenimine-based polyelectrolyte complex. Chem. Commun. 49, 2670-2672 (2013).

25. Tseng, S. J. et al. Environment acidity triggers release of recombinant adenoassociated virus serotype 2 from a tunable matrix. J. Control. Release 170, 252-258 (2013).

26. Moghimi, S. M. et al. A two-stage poly(ethylenimine)-mediated cytotoxicity: implications for gene transfer/therapy. Mol. Ther. 11, 990-995 (2005).

27. Ndoye, A. et al. Eradication of p53-mutated head and neck squamous cell carcinoma xenografts using nonviral p53 gene therapy and photochemical internalization. Mol. Ther. 13, 1156-1162 (2006).

28. Li, D. et al. Construction of a star-shaped copolymer as a vector for FGF receptor-mediated gene delivery in vitro and in vivo. Biomacromolecules 11, 2221-2229 (2010).

29. Xu, L. \& Anchordoquy, T. Drug delivery trends in clinical trials and translational medicine: challenges and opportunities in the delivery of nucleic acid-based therapeutics. J. Pharm. Sci. 100, 38-52 (2011).

30. Ventura, A. et al. Restoration of p53 function leads to tumour regression in vivo. Nature 445, 661-665 (2007).

31. Rubin, A. I., Chen, E. H. \& Ratner, D. Basal-Cell Carcinoma. N. Engl. J. Med. 353, 2262-2269 (2005).

32. Rigual, N. et al. Photodynamic therapy with 3-(10-hexyloxyethyl) pyropheophorbide a for cancer of the oral cavity. Clin. Cancer Res. 19, 6650-6613 (2013).

33. Prout, G. R. et al. Photodynamic therapy with hematoporphyrin derivative in the treatment of superficial transitional-cell carcinoma of the bladder. N. Engl. J. Med. 317, 1251-1255 (1987).

34. Barathan, M. et al. Hypericin-photodynamic therapy leads to interleukin-6 secretion by HepG2 cells and their apoptosis via recruitment of $\mathrm{BH} 3$ interacting-domain death agonist and caspases. Cell Death Dis. 4, e697 (2013).

35. Huggett, M. T. et al. Phase I/II study of verteporfin photodynamic therapy in locally advanced pancreatic cancer. Br.. J. Cancer 110, 1698-1704 (2014).

36. Spechler, S. J. \& Souza, R. F. Barrett's esophagus. N. Engl. J. Med. 371, 836-845 (2014).
37. Akopov, A. et al. Preoperative endobronchial photodynamic therapy improves resectability in initially irresectable (inoperable) locally advanced non small cell lung cancer. Photodiagnosis Photodyn. Ther. 11, 259-264 (2014).

38. Ross, P. et al. Incorporation of photodynamic therapy as an induction modality in non-small cell lung cancer. Lasers Surg. Med. 38, 881-889 (2006).

39. Cai, X. J. et al. Photodynamic therapy for intractable bronchial lung cancer. Photodiagnosis Photodyn. Ther. 10, 672-676 (2013).

40. Begg, A. C., Stewart, F. A. \& Vens, C. Strategies to improve radiotherapy with targeted drugs. Nat. Rev. Cancer 11, 239-253 (2011).

\section{Acknowledgements}

This work was supported through the Taiwan Ministry of Science and Technology Gran (MOST 103-2320-B-110-005-MY2 and NSC 103-2811-B-002-016) and China Medical University grant (CMU103-RAP-02)

\section{Author contributions}

S.-J.T., Z.-X.L., I.M.K. and P.-C.Y. designed the experiments. S.-J.T. and Z.-X.L performed the experiments of complex characterizations. S.-J.T., Z.-X.L. and Y.-F.D. carried out the in vitro cytotoxicity and transfection studies. S.-J.T., S.-H.K., Y.-F.Z., K.-Y.H., H.-J.L. and S.-C.Y. carried out the in vivo animal study. C.-L.Y. and C.-F.H. carried out the Kaplan-Meier survival curve. All authors discussed the results, co-wrote the paper and commented on the manuscript.

\section{Additional information}

Supplementary Information accompanies this paper at http://www.nature.com/ naturecommunications

Competing financial interests: The authors declare no competing financial interests.

Reprints and permission information is available at http://npg.nature.com/ reprintsandpermissions/

How to cite this article: Tseng, S.-J. et al. Highly specific in vivo gene delivery for p53-mediated apoptosis and genetic photodynamic therapies of tumour. Nat. Commun. 6:6456 doi: 10.1038/ncomms7456 (2015).

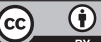

This work is licensed under a Creative Commons Attribution 4.0 International License. The images or other third party material in this article are included in the article's Creative Commons license, unless indicated otherwise in the credit line; if the material is not included under the Creative Commons license, users will need to obtain permission from the license holder to reproduce the material To view a copy of this license, visit http://creativecommons.org/licenses/by/4.0/ 